\title{
Analisis Bukti Serangan Address Resolution Protocol Spoofing menggunakan Metode National Institute of Standard Technology
}

\author{
Imam Riadi $^{1}$, Abdul Fadlil ${ }^{2}$, Muhammad Nasir Hafizh ${ }^{3}$ \\ ${ }^{1}$ Program Studi Sistem Informasi, Universitas Ahmad Dahlan \\ ${ }^{2}$ Program Studi Teknik Elektro, Universitas Ahmad Dahlan \\ ${ }^{3}$ Program Studi Teknik Informatika, Universitas Ahmad Dahlan \\ email: imam.riadi@is.uad.ac.id ${ }^{1}$, fadlil@mti.uad.ac.id²,m1907048019@webmail.uad.ac.id ${ }^{3}$
}

(Received: 19 April 2020/ Accepted: 6 Mei 2020 / Published Online: 20 Juni 2020)

\begin{abstract}
Abstrak
Penelitian ini bertujuan untuk menemukan informasi bukti serangan Address Resolution Protocol (ARP) Spoofing berupa alamat MAC address penyerang dan korban beserta waktu terjadinya serangan. Penelitian ini menggunakan tools wireshark untuk melihat lalu lintas jaringan, terutama pada protokol ARP dan menggunakan metode National Insitute of Standard Technology (NIST) sebagai kerangka kerja selama proses simulasi sampai dengan pembuatan laporan barang bukti. Serangan ARP Spoofing dapat mengakibatkan terjadinya serangan lain, seperti Denial of Service dan Man in The Middle Attack, yanag mana serangan ini memungkinkan pengguna tidak dapat mengakses kedalam jaringan dan terjadinya pencurian data. Pada tahapan simulasi dilakukan 2 serangan ARP Spoofing terhadap 1 perangkat laptop dan 1 perangkat routerboard yang terhubung didalam jaringan. Hasil dari simulasi serangan berhasil ditemukan 2 serangan beserta informasi yang berhasil diperoleh, yaitu alamat MAC address penyerang dan korban beserta waktu terjadinya serangan. Berdasarkan hasil pengujian yang dilakukan, berhasil ditemukan semua serangan ARP Spoofing yang terjadi pada jaringan dengan tingkat keberhasilan $100 \%$.
\end{abstract}

Kata kunci: Address Resolution Protocol, National Institute of Standard Technology, Spoofing

\begin{abstract}
This research intends to find information about evidence of Address Resolution Protocol (ARP) Spoofing attacks that is the MAC address of the attacker and victim also the time of the attack. This research uses Wireshark tools to inspect network traffic, especially on the ARP protocol. It uses the National Institute of Technology Technology (NIST) method as a framework in the simulation process to produce evidence reports. ARP Spoofing attacks can lead to other attacks, such as Denial of Service and Man in the Middle Attack, this attack allows users not to be able to access the network and data theft. During the simulation stage, 2 ARP Spoofing attacks are carried out on 1 laptop and 1 router connected to the network. The results of the attack simulation found 2 attacks and obtained information about the MAC address of the attacker and victim and also the time of the attack. Based on the results of tests carried, successfully found all ARP Spoofing attacks that occur on the network with a success rate of $100 \%$
\end{abstract}

Keywords: Address Resolution Protocol, NIST, Spoofing

\section{PENDAHULUAN}

Pertumbuhan pengguna internet semakin meningkat. Meningkatnya pengguna internet tidak terlepas dari kemudahan yang didapatkan dalam menggunakan internet, seperti halnya dalam komunikasi jarak jauh tidak lagi menjadi kendala pada zaman sekarang ini, begitu juga didalam mengakses informasi, pengguna dapat dengan mudah memberikan dan mendapatkan informasi. Jaringan internet memberikan banyak kemudahan lain, sehingga membuat pengguna tidak menyadari adanya ancaman dari serangan siber pada jaringan komputer atau 
internet. Indonesia (Jayani, 2019), statistik pengguna internet Indonesia diproyeksikan semakin meningkat setiap tahunnya seperti yang terlihat pada gambar 1 .

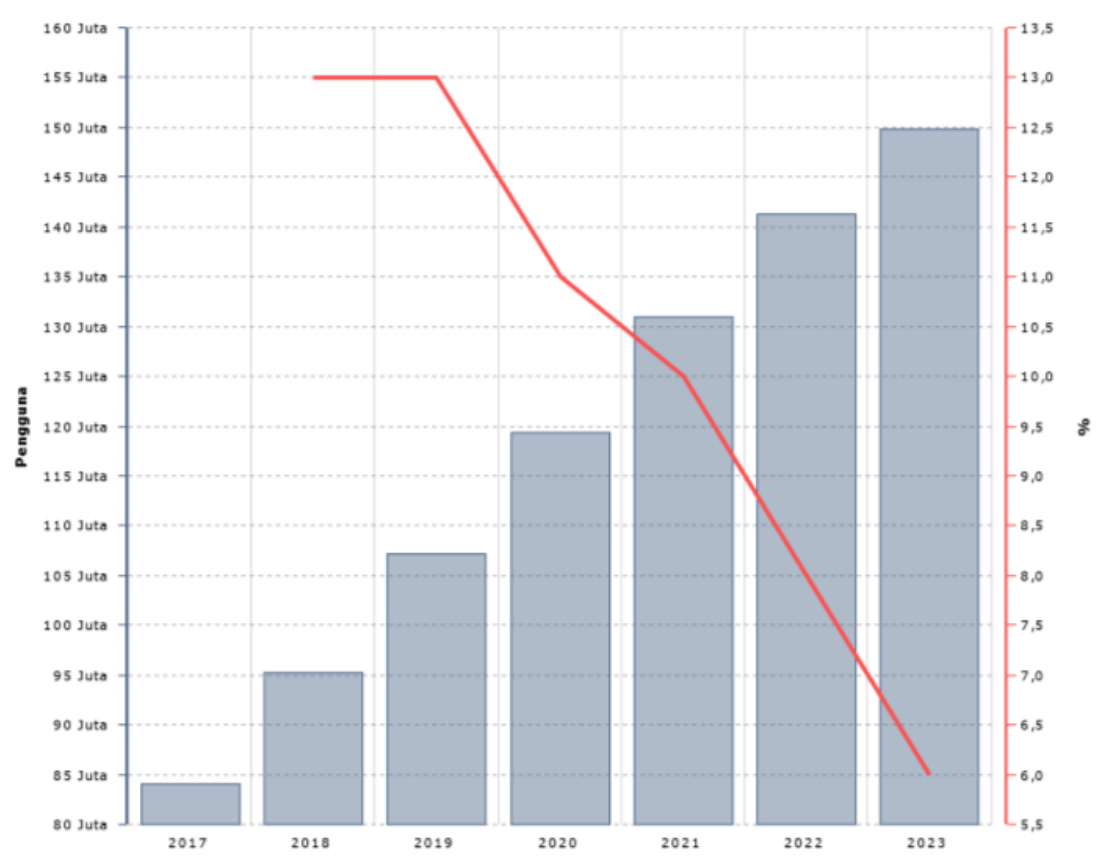

Gambar 1. Statistik Pengguna Internet Indonesia

Pada gambar 1 dapat dilihat tahun 2018 data pengguna internet Indonesia sebanyak 95.2 juta tumbuh sebesar 13,3\%. Pada tahun 2019 pengguna internet Indonesia diproyeksikan sebanyak 107,2 juta tumbuh sebesar 12.6\%. Penelitian (Bitkom, 2018) menyatakan sebesar $47 \%$ dari perusahaan industri mengalami kerusakan dari serangan siber yang didominasi oleh serangan malware sebesar 24\%. Hasil dari penelitian tersebut juga merilis serangan yang terjadi pada perusahaan industri, seperti yang terlihat pada gambar 2.

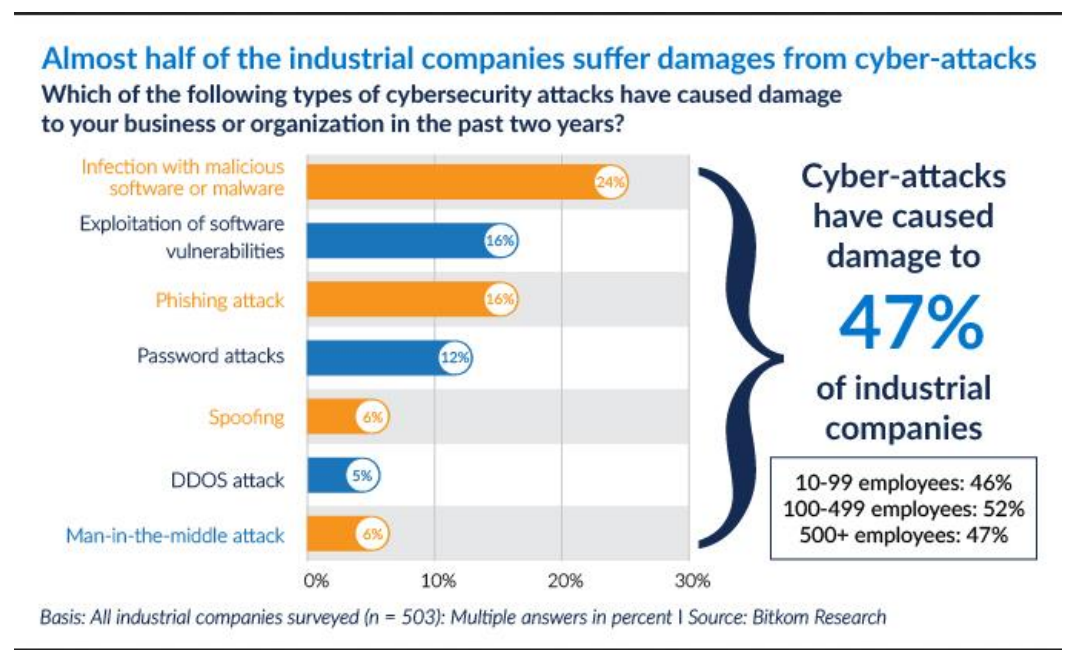

Gambar 2. Rangkuman Persentase Serangan Siber

Kasus yang terjadi pada perusahan industri seperti pencurian email, data pelanggan dan data keuangan. Serangan dengan metode spoofing juga merupakan salah satu serangan yang terjadi pada kasus kerusakan perusahaan industri diatas, dengan presentase serangan spoofing sebesar $6 \%$. 
Pada jaringan komputer terdapat protocol yang berfungsi sebagai penerjemah alamat IP address ke alamat MAC address, yang disebut Address Resolution Protocol (ARP), Protocol ARP bekerja dengan mengirimkan permintaan ARP secara broadcast untuk mencari alamat MAC address host yang dituju, metode pengiriman ARP secara broadcast ini merupakan celah sehingga dimanfaatkan oleh penyerang untuk memalsukan alamat MAC address host yang dituju. (Susianto, 2015). Penelitian yang dilakukan oleh (Veny Charnita $\mathrm{Br}$ Ginting, Mahendra Data, 2019) ARP Spoofing merupakan kejahatan siber atau serangan yang terjadi pada jaringan komputer dengan cara memalsukan alamat MAC address penerima. Peneliti melakukan pemerikasaan paket ARP dengan sebuah detektor host. Hasil dari penelitian ini merupakan akurasi presentase deteksi sebesar 89,64\% dan waktu rata-rata deteksi adalah 0.4 detik. Penelitian juga dilakukan oleh (Kamajaya et al., 2020) dengan judul Analisa Investigasi Static Forensics Serangan Man In The Middle Berbasis ARP Poisoning, Hasil dari penelitian ini untuk menemukan data dan menemukan barang bukti.

Penelitian forensik jaringan telah dilakukan juga untuk mendeteksi flooding attack pada web server (Mualfah \& Riadi, 2017). Pada penelitian tersebut, peneliti menerapkan sistem pendeteksi Intrusion Detection System (IDS) seperti snort yang merupakan sebuah tools digunakan untuk mendeteksi flooding attack. Semua aktifitas lalu lintas jaringan, nantinya akan tersimpan didalam log file, kemudian akan dilakukan analisis atau investigasi terhadap log file tersebut.

Forensik jaringan adalah ilmu yang berfokus pada jaringan komputer dan perangkat yang terhubung didalamnya, dalam upaya untuk menemukan informasi penyerang dan untuk mencari bukti atas serangan (Mazdadi et al., 2017). Menurut Rizal et al. (2018) Network Forensics merupakan proses mengambil, merekam serta menganalisis kegiatan pada lalu lintas jaringan untuk menemukan sumber serangan atau masalah lainnya. Pengambilan barang bukti pada digital forensic dapat dilakukan dengan cara dead forensic dan live forensic.(Yuwono et al., 2019). Dead forensic mengambil bukti digital yang tersimpan dimedia penyimpanan seperti log file, sedangkan live forensic mengambil bukti digital disaat system sedang menyala.

Penelitian dengan metode live forensic dilakukan oleh (Riadi, et al., 2018) dengan judul Identifikasi Bukti Digital WhatsApp pada Sistem Operasi Proprietary Menggunakan Live Forensics, penelitian ini menghasilkan barang bukti terkait kasus penipuan online dengan menggunakan tool ftk imager. Peneliti mengambil dan menganalisis data pada RAM, berupa percakapan WhatsApp (Riadi et al., 2019)

Kerangka kerja dalam penyusunan laporan investigasi suatu kasus dapat dilakukan dengan beberapa metode, diantaranya menggunakan metode National Institute of Justice (NIJ) dan National Institute of Standard Technology (NIST). Penelitian dengan metode NIJ dilakukan oleh (Riadi et al., n.d.) dengan judul Review Proses Forensik Optical Drive Menggunakan Metode National Institute of Justice (NIJ), penelitian ini mengembalikan hasil dari file yang telah diformat dengan menggunakan tool autopsy, untuk mendapatkan bukti digital. Penelitian dengan metode National Institute of Standard Technology dilakukan oleh (Riadi, Yudhana, et al., 2017) dengan judul Analisis Recovery Bukti Digital Instagram Messangers Menggunakan Metode National Institute Of Standards And Technology (NIST), hasil yang dari penelitian ini diharapkan mendapatkan barang bukti gambar dan pesan yang telah dihapus dengan menggunakan tool recovery.(Riadi, Yudhana, et al., 2018). Penelitian dengan menggunakan metode NIST juga dilakukan oleh (Syahib et al., 2020) dengan judul Akuisisi Bukti Digital Aplikasi Viber Menggunakan Metode National Institute of Standards Technology (NIST), dalam penelitian ini data yang berhasil didapatkan antar lain, akun pelaku, daftar kontak, riwayat panggilan, teks percakapan, dan pesan gambar/video. Metode NIST juga dilakukan oleh (Riadi, Umar, et al., 2017) hasil penelitian diperoleh rekaman percakapan, BBM Identification Number (BBM PIN), nama pengirim dan penerima, dan 
waktu percakapan. Penelitian mengenai serangan Distrbuted Denial of Service dilakukan oleh(Aji et al., 2017) dengan judul Pengembangan Sistem Pengaman Jaringan Komputer Berdasarkan Analisis Forensik Jaringan, penelitian tersebut mengenai serangan Distributed Denial of Service, yang menghasilkan data penyerang, dan waktu terjadinya serangan. (Fadlil et al., 2017)

Berdasarkan paparan masalah diatas, penelitian mengenai serangan ARP Spoofing dilakukan untuk mengidentifikasi penyerang dan korban sehingga admin jaringan dapat meningkatkan keamanan pada jaringan. Penelitian ini bertujuan untuk menemukan informasi bukti serangan Address Resolution Protocol (ARP) Spoofing berupa alamat MAC address penyerang dan korban beserta waktu terjadinya serangan.

\section{METODE}

Metode yang digunakan dalam penelitian ini menggunakan metode National Institute of Standards and Technology (NIST) yang merupakan metode dalam menganalisis bukti digital. Metode NIST memiliki beberapa tahapan dalam proses analisis bukti digital, seperti yang terdapat pada gambar 3 (Riadi, Yudhana, et al., 2017).

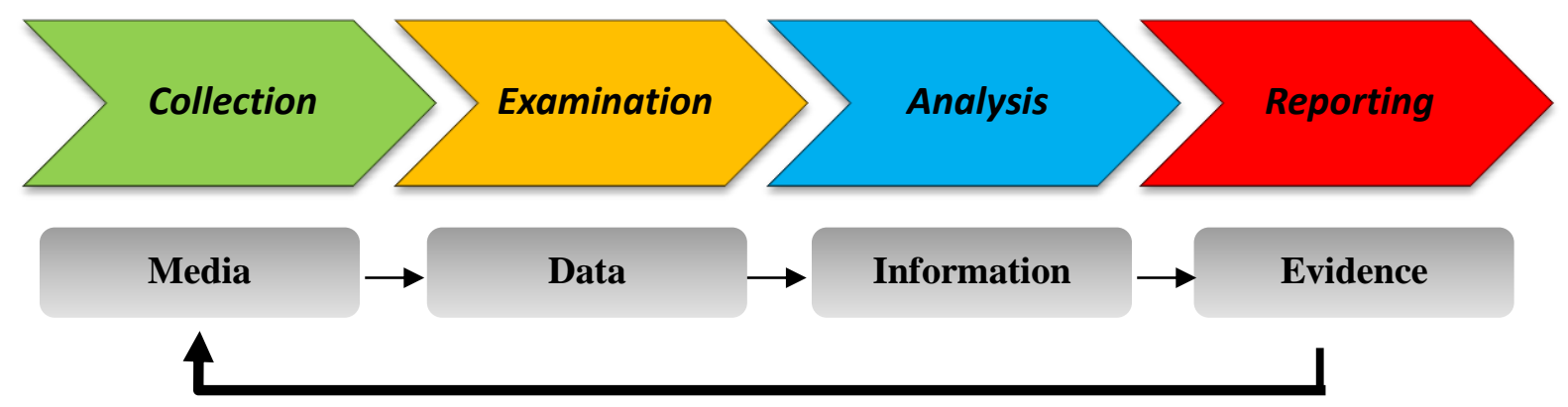

Gambar 3. NIST Alur Proses

Pada gambar 2 dapat dilihat tahapan -tahapan pada proses analisis bukti digital :

\section{Collection}

Tahap koleksi melakukan pengumpulan data, baik data literasi maupun data real simulasi. Pada tahap ini dilakukan identifikasi dan pengumpulan data dari proses simulasi dengan cara melakukan scanning pada jaringan.

\section{Examinatain}

Tahap examination merupakan tahap pemeriksaan terhadap data yang diperoleh dari hasil scanning pada jaringan, terutama pada protocol ARP.

3. Analysis

Tahap Analisis melakukan analisis dari hasil pemeriksaan dengan menggunakan metode legal dan dibenarkan untuk mendapatkan informasi yang berguna dan dijadikan jawaban dari pertanyaan yang dapat mendorong pengumpulan dan pemeriksaan.

\section{Reporting}

Tahap pelaporan merupakan tahap melaporkan hasil analisis, yang meliputi jenis serangan, alamat IP address pelaku dan korban, alamat MAC address pelaku dan korban, serta waktu terjadinya serangan.

Penelitian ini menggunakan alat dan bahan berupa hardware dan software yang digunakan saat proses simulasi dan pengambilan data. 
Tabel 1. Alat dan Bahan Penelitian

\begin{tabular}{|c|c|}
\hline Hardware dan Software & Keterangan \\
\hline Notebook NF210 & $\begin{array}{c}\text { Sebagai komputer yang digunakan untuk melakukan } \\
\text { serangan ARP spoofing }\end{array}$ \\
\hline ASUS Notebook A456U & $\begin{array}{c}\text { Sebagai komputer yang digunakan sebagai } \\
\text { investigator }\end{array}$ \\
\hline Mikrotik Routerboard & $\begin{array}{l}\text { Smart router yang digunakan untuk menghubungkan } \\
\text { jaringan dengan internet }\end{array}$ \\
\hline Wireshark & $\begin{array}{l}\text { Network Protocol Tool Analyzer, tool yang digunakan } \\
\text { untuk menganalisa lalu lintas paket pada jaringan }\end{array}$ \\
\hline Ettercap & $\begin{array}{l}\text { Tool yang digunakan untuk melakukan serangan arp } \\
\text { spoofing }\end{array}$ \\
\hline
\end{tabular}

Pada tabel 2 disebutkan beberapa alat dan bahan yang digunakan dalam penelitian berupa hardware dan software. Alat dan bahan ini dikonfigurasi kedalam jaringan sesuai dengan topologi untuk memulai simulasi.

\section{HASIL DAN PEMBAHASAN \\ Collection (Pengumpulan Data)}

Pada tahap ini dilakukan pengumpulan data dari literasi. Pengumpulan data juga dilakukan dengan melakukan simulasi seragan ARP Spoofing dengan cara melakukan scanning lalu lintas jaringan menggunakan tools wireshark. ARP Spoofing menyerang dengan memanipulasi alamat MAC address perangkat yang terhubung didalam jaringan, sehingga yang dikirim oleh host akan terlebih dahulu menuju kepada alamat MAC address penyerang. Isustrasi menegani serangan ARP Spoofing dapat dilihat pada gambar 4.

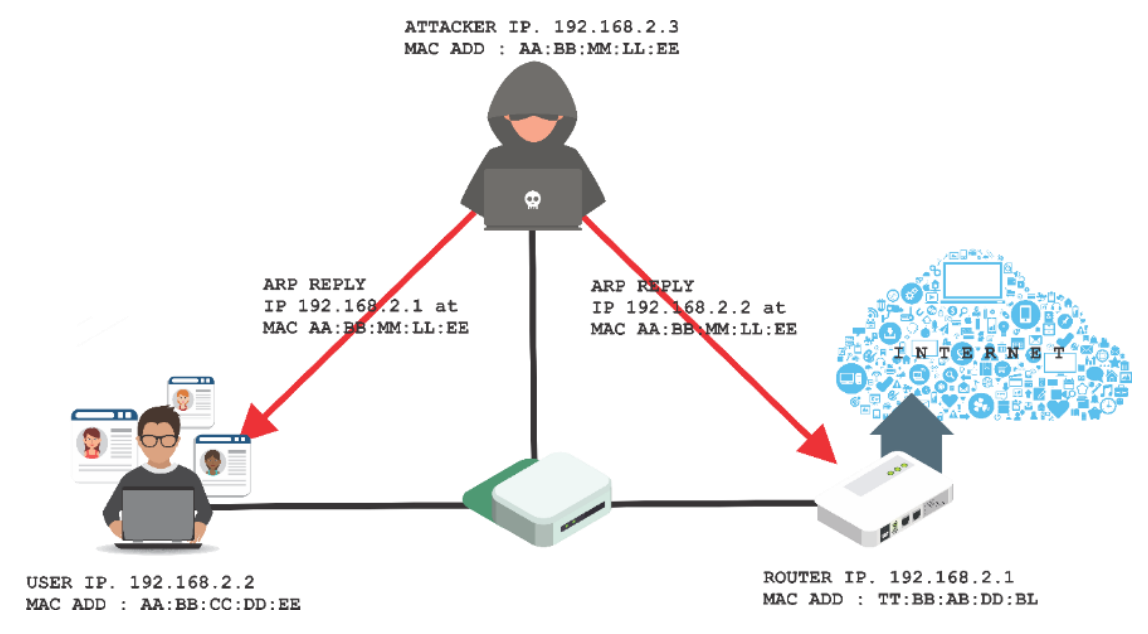

Gambar 4. Ilustrasi Serangan ARP Spoofing

Pada gambar 4 dapat dilihat, attacker mengirimkan ARP reply kepada user dan router untuk memanipulasi alamat MAC address penerima, sehingga paket yang dikirim akan melewati alamat MAC address attacker. Simulasi dan perangkat yang terhubung didalam jaringan dibuat sesuai dengan topologi yang digunakan dalam penelitian ini, topologi yang digunakan dalam jaringan in dapat dilihat pada gambar 5. 


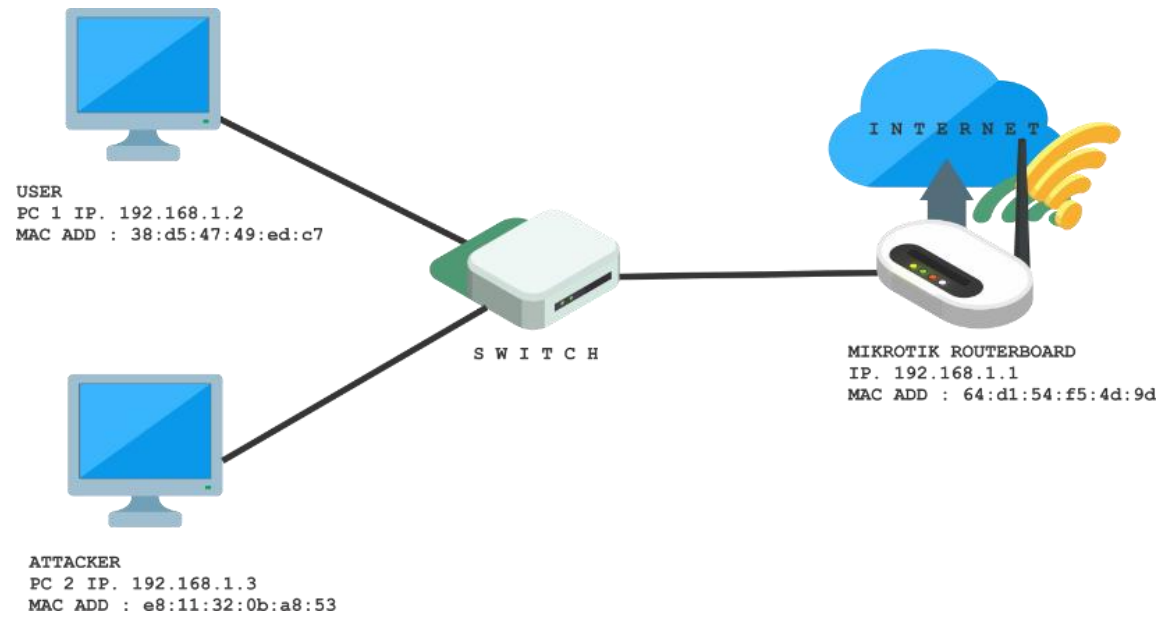

Gambar 5. Topologi Simulasi Pengambilan Data

Pada gambar 5 diatas dapat dilihat perangkat yang terhubung dalam topologi jaringan yang digunakan dalam simulasi dalam kaitannya untuk mendapatkan informasi mengenai serangan ARP Spoofing. Pada tabel 2 dipaparkan pengaturan alamat IP address pada tiap perangkat dan informasi alamat MAC address pada tipa perangkat.

Tabel 2. Tabel Identitas Perangkat

\begin{tabular}{cccc}
\hline Perangkat & Ip Address & MAC Address & Keterangan \\
\hline $\begin{array}{c}\text { Routerboard } \\
\text { Mikrotik }\end{array}$ & 192.168 .1 .1 & $64: \mathrm{d} 1: 54: \mathrm{f5}: 4 \mathrm{~d}: 9 \mathrm{~d}$ & $\begin{array}{c}\text { Sebagai router dan } \\
\text { gateway }\end{array}$ \\
PC 1 & 192.168 .1 .2 & $38: \mathrm{d} 5: 47: 49: \mathrm{ed}: \mathrm{c} 7$ & $\begin{array}{c}\text { Sebagai PC Client } \\
\text { dengan } \text { system }\end{array}$ \\
ASUS & & & operasi Windows \\
Notebook & & & 10 \\
A456U & & $\mathrm{e} 8: 11: 32: 0 \mathrm{~b}: \mathrm{a} 8: 53$ & $\begin{array}{c}\text { Sebagai PC } \\
\text { Attacker } \text { dengan } \\
\text { PC 2 }\end{array}$ \\
Samsung & 192.168 .1 .3 & & system operasi \\
Notebook & & & Kali Linux \\
\hline
\end{tabular}

\section{Examintation (Pemerikasaan Data)}

Pada tahapan ini dilakukan pengumpulan data dari serangan simulasi yang dibuat. Pengumpulan data dilakukan dengan melakukan scanning pada jaringan dengan menggunakan wireshark. Terdiri dari beberapa protocol yang berhasil didapat, Pada gambar 6 terlihat lalu lintas paket data dan protokol yang berhasil didapatkan. Protokol yang berhasil didapat antara lain Spanning Tree Protocol (STP), Cisco Discovery Protocol (CDP) dan Address Resolution Protocol (ARP). 




Gambar 6. Tampilan Data Hasil Scanning Jaringan

\section{Analysis (Analisis)}

Pada tahap ini data yang berhasil dari tahap sebelumnya (examintaion) diproses kembali dengan hanya melihat pada protocol ARP untuk mencari serangan ARP spoofing. Lalu lintas jaringan normal terjadi ketika alamat MAC address yang dituju sesuai dengan alamat yang sebenarnya, dapat dilihat pada gambar 7 .

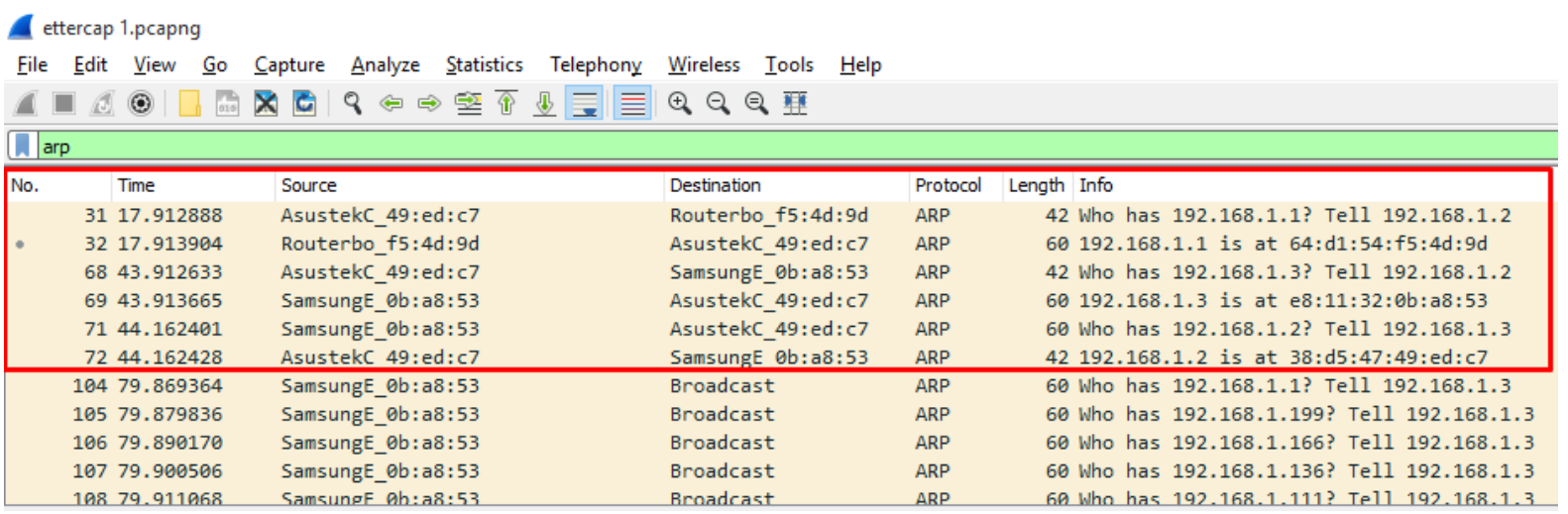

\section{Gambar 7. Proses Capture Lalu Lintas Jaringan Normal}

Pada gambar 7 baris nomor 31, PC 1 menghubungi router, terlihat pada kolom source (pengirim/PC1) menghubungi IP address 192.168.1.1 (routerboard). Routerbard memberikan balasan, pada baris no 32, bahwa IP address 192.168.1.1 berada pada MAC address 64:d1:54:f5:4d:9d. Lalu lintas jaringan tidak normal terjadi ketika alamat MAC address yang dituju tidak sesuai dengan alamat yang sebenarnya, atau menuju kepada alamat PC penyerang, dapat dilihat pada gambar 8.

\begin{tabular}{|lllll} 
Q \\
Eiltercap 1.pcapng
\end{tabular}

Gambar 8. Proses Capture Lalu Lintas Jaringan ARP Spoofing 
Pada gambar 8 PC 2 (MAC address e8:11:32:0b:a8:53) memberikan broadcast pada PC 1 (MAC address 38:d5:47:49:eD:c7), bahwa router (IP address 192.168.1.1) berada pada MAC address PC 2 (MAC address e8:11:32:0b:a8:53). Hasil dari scanning jaringan menggunakan wireshark, mendapatkan informasi, berupa waktu terjadinya serangan, MAC address penyerang dan korban, sehingga dapat membantu investigator dalam membuat laporan kasus penyerangan ARP spoofing pada jaringan.

\section{Report (Laporan)}

Pada tahap ini hasil yang didapatkan dari tahapan analisis disajikan dalam bentuk laporan. Laporan yang disajikan terdiri dari informasi mengenai serangan yaitu sumber serangan dan korban beserta waktu terjadinya serangan.

\section{SIMPULAN}

Pengujian yang dilakukan dengan metode NIST dimulai dengan mengumpulkan informasi study literature dan membuat simulasi dengan tujuan untuk mengidentifikasi serangan ARP Spoofing. Pada tahapan simulasi dilakukan 2 serangan ARP Spoofing terhadap 1 perangkat laptop dan 1 perangkat routerboard yang terhubung didalam jaringan. Hasil dari simulasi serangan berhasil ditemukan 2 serangan beserta informasi yang berhasil diperoleh, yaitu alamat MAC address penyerang dan korban beserta waktu terjadinya serangan. Berdasarkan hasil pengujian yang dilakukan berhasil ditemukan semua serangan ARP Spoofing yang terjadi pada jaringan dengan tingkat keberhasilan 100\%.

\section{REFERENSI}

Aji, S., Fadlil, A., \& Riadi, I. (2017). Pengembangan Sistem Pengaman Jaringan Komputer Berdasarkan Analisis Forensik Jaringan. Jurnal Ilmiah Teknik Elektro Komputer Dan Informatika, 3(1), 11. https://doi.org/10.26555/jiteki.v3i1.5665

Didi Susianto, I. Y. (2015). Mengamankan Wireless Dengan Menggunakan Two Factor, Password dan Mac Address Filtering. Jurnal Manajemen Sistem Informasi Dan Teknologi Volume, 05(02), 31-36.

Fadlil, A., Riadi, I., \& Aji, S. (2017). Review of detection DDOS attack detection using naive bayes classifier for network forensics. Bulletin of Electrical Engineering and Informatics, 6(2), 140-148. https://doi.org/10.11591/eei.v6i2.605

Jayani, D. H. (2019). Berapa Pengguna Internet di Indonesia? Databoks, 1. https://databoks.katadata.co.id/datapublish/2019/09/09/berapa-pengguna-internet-diindonesia

Kamajaya, G. E. A., Riadi, I., Prayudi, Y., \& Dahlan, U. A. (2020). Analisa Investigasi Static Forensics Serangan Man In The Arp Poisoning Based On Man In The Middle Attack In Static. 3(1), 6-12. https://doi.org/10.33387/jiko

Mazdadi, M. I., Riadi, I., \& Luthfi, A. (2017). Live Forensics on RouterOS using API Services to Investigate Network Attacks. International Journal of Computer Science and Information Security (IJCSIS), 15(2), 406-410.

Mualfah, D., \& Riadi, I. (2017). Network Forensics For Detecting Flooding Attack On Web Server. IJCSIS) International Journal of Computer Science and Information Security, 15(2), 326-331. https://doi.org/10.1016/j.ecss.2004.08.013

Riadi, I., Fadlil, A., \& Aulia, M. I. (n.d.). Review Proses Forensik Optical Drive Menggunakan Metode National Institute of Justice ( NIJ ).

Riadi, I., Sunardi, S., \& Rauli, M. E. (2018). Identifikasi Bukti Digital WhatsApp pada Sistem Operasi Proprietary Menggunakan Live Forensics. Jurnal Teknik Elektro, 10(1), 18-22. https://doi.org/10.15294/jte.v10i1.14070

Riadi, I., Sunardi, S., \& Rauli, M. E. (2019). Live Forensics Analysis of Line App on Proprietary Operating System. Kinetik: Game Technology, Information System, 
Computer Network, Computing, Electronics, and Control, 4(4), 305-314. https://doi.org/10.22219/kinetik.v4i4.850

Riadi, I., Umar, R., \& Firdonsyah, A. (2017). Identification of Digital Evidence on Android's Blackberry Messenger using NIST Mobile Forensic Method. International Journal of Computer Science and Information Security (IJCSIS), 15(5), 3-8.

Riadi, I., Yudhana, A., Caesar, M., \& Putra, F. (2017). Analisis Recovery Bukti Digital Instagram Messangers Menggunakan Metode National Institute of Standards and Technology (Nist). Seminar Nasional Teknologi Informasi Dan Komunikasi SEMANTIKOM, 161-166.

Riadi, I., Yudhana, A., Caesar, M., \& Putra, F. (2018). Akuisisi Bukti Digital Pada Instagram Messenger Berbasis Android Menggunakan Metode National Institute Of Justice (NIJ). 4, 219-227.

Rizal, R., Riadi, I., \& Prayudi, Y. (2018). Network Forensics for Detecting Flooding Attack on Internet of Things ( IoT ) Device. International Journal of Cyber-Security and Digital Forensics (IJCSDF), 7(4), 382-390.

Syahib, M. I., Riadi, I., \& Umar, R. (2020). Akuisisi Bukti Digital Aplikasi Viber Menggunakan Metode National Institute of Standards Technology (NIST). Jurnal Sains Komputer \& Informatika (J-Sakti), 4(1), 170-178.

Veny Charnita Br Ginting, Mahendra Data, D. P. K. (2019). Deteksi Serangan ARP Spoofing berdasarkan Analisis Lalu Lintas Paket. 3(5), 5049-5057.

Yuwono, D. T., Fadlil, A., \& Sunardi, S. (2019). Performance Comparison of Forensic Software for Carving Files using NIST Method. Jurnal Teknologi Dan Sistem Komputer, 7(3), 89. https://doi.org/10.14710/jtsiskom.7.3.2019.89-92 